\title{
Comunicação
}

\section{Produtividade e qualidade de frutos de pepino africano em resposta à adubação nitrogenada}

\author{
Guilherme Antunes ${ }^{1}$, Ana Paula Sato Ferreira ${ }^{2}$, Mário Puiatti ${ }^{3}$ Paulo Roberto Cecon ${ }^{4}$, \\ Geovani do Carmo Copati da Silva
}

\begin{abstract}
RESUMO
O pepino africano (Cucumis metuliferus) é uma planta nativa do continente africano, com potencial para comércio internacional, destinado tanto ao consumo, na forma de sucos, como ao uso farmacêutico. Todavia, pouco se sabe sobre seu manejo cultural, em nossas condições, sobretudo quanto à adubação nitrogenada. Objetivou-se, com este trabalho, avaliar o efeito de doses de nitrogênio sobre o crescimento da planta, a produtividade e a qualidade de frutos. $\mathrm{O}$ trabalho foi conduzido em casa de vegetação, em vasos de $10 \mathrm{~L}$. Constou de seis tratamentos, correspondentes às doses de $\mathrm{N}$ de $0,40,80,120,160$ e $200 \mathrm{~kg} \mathrm{ha}^{-1}$, distribuídas no delineamento inteiramente casualizado, com 11 repetições. Avaliaram-se: produção de frutos, massas de matéria seca de parte aérea e de raízes e características físicas e químicas de frutos. $\mathrm{O}$ número de frutos e a massa de matéria fresca de frutos apresentaram valores máximos estimados de 2,24 frutos/planta e de 516,41 g/planta, respectivamente, com as doses de 122,50 e de 154,44 $\mathrm{kg} \mathrm{ha}^{-1} \mathrm{de}$ N. A massa média de fruto estimada foi de 240,27 $\mathrm{g} /$ fruto, obtida com a dose máxima testada (200 $\mathrm{kg} \mathrm{ha}^{-1} \mathrm{de} \mathrm{N}$ ). A massa seca de parte aérea teve máximo estimado de 39,12 $\mathrm{g} /$ planta, com a dose de $144,0 \mathrm{~kg} \mathrm{ha}^{-1} \mathrm{de} \mathrm{N}$. As doses de $\mathrm{N}$ não interferiram na qualidade dos frutos. Para o cultivo do pepino africano, sugere-se a dose de $154,44 \mathrm{~kg} \mathrm{ha}^{-1} \mathrm{de} \mathrm{N}$, que proporciona 2,18 frutos/ planta, com massa média de 237,07 g/fruto, e produtividade estimada de 516,41 g/planta.
\end{abstract}

Palavras-chave: Cucumis metuliferus, Kiwano, pepino chifrudo, produção.

\section{ABSTRACT}

\section{Yield and quality of horned cucumber in response to nitrogen fertilization}

African horned cucumber (Cucumis metuliferus) is native from Africa and has great potential for international trade of both juice consumption and pharmaceutical uses. However, little is known about the crop management in our conditions, particularly in terms of nitrogen fertilization. This study aimed to evaluate the optimal $\mathrm{N}$ level for plant growth and fruit yield as well as fruit quality. The experiment was conducted in a greenhouse using $10 \mathrm{~L}$ pots. The experimental arrangement was a completely randomized design with six treatments corresponding to the $\mathrm{N}$ rates 0,40 , $80,120,160,200 \mathrm{~kg} \mathrm{ha}^{-1}$, with 11 replications. The variables evaluated included fruit yield, shoot dry matter, root dry matter and physical and chemical characterization of the fruits. The number of fruits and weight of fresh matter of fruits per plant presented maximum values of 2.24 fruits/plant and $516.41 \mathrm{~g} /$ plant, respectively, for the rates of 122.50 and $154.44 \mathrm{~kg} \mathrm{ha}^{-1} \mathrm{~N}$. The average weight of fruit was estimated at $240.27 \mathrm{~g} /$ fruit at the maximum N level tested (200 kg ha${ }^{1} \mathrm{~N}$ ). The highest shoot dry matter was $39.12 \mathrm{~g} / \mathrm{plant}$ at $144.00 \mathrm{~kg} \mathrm{ha}^{-1} \mathrm{~N}$. The $\mathrm{N}$ levels did not influence the quality of the fruits. For the cultivation of African cucumber, we recommend the rate of $154.44 \mathrm{~kg} \mathrm{ha}^{-1} \mathrm{~N}$ that provides 2.18 fruits/ plant with average mass of $237.07 \mathrm{~g} /$ fruit and yield estimated at $516.41 \mathrm{~g} / \mathrm{plant}$.

Key words: Cucumis metuliferus, Kiwano, African horned cucumber, production.

\footnotetext{
Recebido para publicação em 19/10/2012 e aprovado em 30/08/2013.

${ }^{1}$ Engenheiro-Agrônomo. Departamento de Fitotecnia, Universidade Federal de Viçosa, Campus Viçosa, Avenida Peter Henry Rolfs, s/n, 36570-000, Viçosa, Minas Gerais, Brasil. agro_gui@yahoo.com.br

${ }^{2}$ Engenheira-Agrônoma, Doutora. Departamento de Fitotecnia, Universidade Federal de Viçosa, Campus Viçosa, Avenida Peter Henry Rolfs, s/n, 36570-000, Viçosa, Minas Gerais,Brasil. ana.sato@ufv.br

${ }^{3}$ Engenheiro-Agrônomo, Doutor. Departamento de Fitotecnia, Universidade Federal de Viçosa, Campus Viçosa, Avenida Peter Henry Rolfs, s/n, 36570-000, Viçosa, Minas Gerais, Brasil.mpuiatti@ufv.br (autor correspondente).

${ }^{4}$ Engenheiro-Agrônomo, Doutor. Departamento de Estatística, Universidade Federal de Viçosa, Campus Viçosa, Avenida Peter Henry Rolfs, s/n, 36570-000, Viçosa, Minas Gerais, Brasil. cecon@ufv.br

${ }^{5}$ Acadêmico do curso de Agronomia. Departamento de Fitotecnia, Universidade Federal de Viçosa, Campus Viçosa, Avenida Peter Henry Rolfs, s/n, 36570-000, Viçosa, Minas Gerais, Brasil. geovani.silva@ufv.br
} 


\section{INTRODUÇÃO}

O pepino africano (Cucumis metuliferus) é uma espécie da família Cucurbitaceae, que tem como origem as regiões semiáridas sul e central do continente africano (Robinson \& Decker-Walters, 1997). É conhecido também como pepino africano chifrudo, pepino de espinhos, Kino, Kiwano ou Melano (Romero-Rodriguez et al., 1992; Benzioni et al., 1993; Robinson \& Decker-Walters, 1997), sendo os dois últimos introduzidos como nome comercial por produtores da Nova Zelândia e Israel, respectivamente (NRC, 2008).

A planta é herbácea, de ciclo anual, muito pilosa, trepadeira ou rasteira, cujo caule cresce de um a três metros, folhas verdes, alongadas e cordiformes, com gavinhas nas axilas. As flores são pequenas, amarelas, unissexuais e estão presentes na mesma planta (Robinson \& DeckerWalters, 1997; NRC, 2008). A polinização é entomófila, realizada por abelhas melíferas, todavia de baixa eficiência, pois ainda não se tem conhecimento de um polinizador ideal para Cucumis metuliferus (NRC, 2008).

Os frutos são ligeiramente alongados, na forma de um elipsoide, com cerca de 10 a $15 \mathrm{~cm}$ de comprimento. A casca, verde-clara, inicialmente, torna-se amareloalaranjada após o amadurecimento, podendo chegar a um alaranjado muito intenso. Apresenta espinhos piramidais, com cerca de um cm de comprimento, em toda a extensão do fruto. A polpa, verde-clara, translúcida, com muitas sementes (Romero-Rodriguez et al., 1992; Robinson \& Decker-Walters, 1997; NRC, 2008), é a porção utilizada para confecção de sucos, cujo efeito medicinal tem sido motivo de várias pesquisas, sobretudo em países do continente africano (Jimam et al., 2010; Wannang et al., 2007). A planta de Cucumis metuliferus também apresenta o potencial para ser empregada como porta-enxerto para outras cucurbitáceas, como melão e pepino, sobretudo por ser considerada tolerante aos nematoides do gênero Meloidogyne (Sigüenza et al., 2005).

Atualmente, o maior produtor mundial de Kiwano é a Nova Zelândia, seguida por Israel. A maior parte dos frutos é comercializada nos Estados Unidos e Europa, com o intuito decorativo; porém, podem ser consumidos in natura, na forma de sucos e saladas acompanhando carnes ou peixes (Benzioni, 1997). Introduzido na Austrália e Nova Zelândia nos anos 70, virou planta daninha na região, principalmente em cultivos de cana-de-açúcar (Benzioni, 1997; Robinson \& Decker-Walters, 1997). O Brasil apresenta condições climáticas necessárias para a produção dessa fruta exótica tropical. No entanto, informações agronômicas sobre a cultura e seu cultivo são limitadas, especialmente quanto às exigências em termos de fertilização nitrogenada.
O N é um dos nutrientes absorvidos em maior quantidade por espécies olerícolas; responsável pelo crescimento e desenvolvimento, atua diretamente na relação fontedreno e distribuição de assimilados entre a parte vegetativa e reprodutiva (Huett \& Dettmann, 1991). Assim, a produtividade das culturas é fortemente relacionada com a fertilização nitrogenada. Por sua vez, os fertilizantes nitrogenados consomem grandes quantidades de energia em sua produção, além de seu excesso ser prejudicial ao ambiente. Portanto, o uso racional desses fertilizantes, visando a aumentar a eficiência de uso do $\mathrm{N}$ pelas plantas é essencial para o desenvolvimento sustentável da agricultura (Xu et al., 2012).

Em cucurbitáceas, como o melão, o aumento da dose de $\mathrm{N}$, até determinado limite, estimula o crescimento e o incremento da área foliar da planta e, consequentemente, proporciona aumento de produtividade (Coelho et al., 2003; Fogaça et al., 2007; Queiroga et al., 2007) e do teor de sólidos solúveis dos frutos (Queiroga et al., 2007). Por outro lado, o incremento das doses de $\mathrm{N}$ pode levar a um aumento da severidade de algumas doenças em cucurbitáceas, como míldio e Didymella (Santos et al., 2009), visto que altas concentrações de $\mathrm{N}$ na planta reduzem a produção de compostos fenólicos e de lignina nas folhas e incrementam a concentração de aminoácidos e de aminas no apoplasto e superfície das folhas, favorecendo as infecções fúngicas (Marschner, 1986).

Em cucurbitáceas, a resposta à adubação nitrogenada tem sido muito variável, em função da espécie, do cultivar e do ambiente de cultivo. Nas culturas do melão (Coelho et al., 2003; Fogaça et al., 2007; Queiroga et al., 2007), melancia (Andrade Junior et al., 2006) e maxixe (Oliveira et al., 2008), têm sido verificados, com a elevação das doses de $\mathrm{N}$, aumentos do número e da massa média de fruto e da produtividade. Máximas produtividades físicas têm sido encontradas com doses de $\mathrm{N}$ de $260 \mathrm{~kg} \mathrm{ha}^{-1}$, para abóbora híbrida, tipo 'Tetsukabuto' (Pôrto et al., 2011a), e de 331 $\mathrm{kg} \mathrm{ha}^{-1}$, para abobrinha cv. Caserta, ambas cultivadas a campo (Pôrto et al., 2012). Para melancia, pertencente à espécie Citrullus lanatus, máxima produtividade foi obtida com 144,76 kg ha-1 de N, em área de savana, em Roraima (Barros et al., 2012), e com 104,48 kg ha-1 , em Neossolo Quartzarênico Órtico típico, no Piauí (Andrade Junior et al., 2006).

Em espécies do gênero Cucumis, como é o caso dos melões e de pepinos, máximas produtividades físicas têm sido encontradas com 312 e $344 \mathrm{~kg} \mathrm{ha}^{-1}$, para o melão Cantaloupe, cultivado em ambiente protegido e a campo, respectivamente (Coelho, et al., 2003); de 287,1 a 309,7 kg $\mathrm{ha}^{-1}$, para variedades de melão Cantaloupe, cultivadas em ambiente protegido (Queiroga et al., 2007); de $160 \mathrm{~kg} \mathrm{ha}^{-1}$, para meloeiro cultivado a campo, em solo arenoso dos Tabuleiros Costeiros do Piauí (Sousa et al., 2005) e de 180 
$\mathrm{kg} \mathrm{ha}^{-1}$, para meloeiro cultivado a campo, em Vertissolo (Faria et al., 2000). Para pepino japonês, cultivado em ambiente protegido, Pôrto et al. (2011b) encontraram máxima produtividade com dose de $402 \mathrm{~kg} \mathrm{ha}^{-1}$ de $\mathrm{N}$.

Na literatura, não foram encontrados trabalhos de pesquisa realizados com a fertilização nitrogenada da cultura do pepino africano (Cucumis metuliferus). Em razão do exposto, este trabalho teve como objetivo avaliar a produtividade e a qualidade de frutos de pepino africano, em resposta à adubação nitrogenada.

\section{MATERIAL E MÉTODOS}

O trabalho foi conduzido em casa de vegetação, no Departamento de Fitotecnia da Universidade Federal de Viçosa, em Viçosa, MG, de novembro de 2010 a fevereiro de 2011. As mudas de pepino africano (Cucumis metuliferus) foram obtidas em bandejas de isopor de 128 células, preenchidas com substrato comercial (Topstrato®). A semeadura foi realizada em 10/11/2010, colocando-se duas sementes por célula; após 15 dias da semeadura, foi feito o desbaste, deixando-se apenas uma planta por célula.

Aos 21 dias após a semeadura, as mudas, com duas folhas definitivas, foram transplantadas para vasos plásticos de $10 \mathrm{~L}$ de capacidade, preenchidos com solo, Argissolo Vermelho-Amarelo, textura argilosa, com as seguintes características químicas: $\mathrm{pH}$ em água $(1: 2,5)=$ 5,$7 ; \mathrm{P}=20,4 \mathrm{mg} \mathrm{dm}^{-3}$ e P-rem $=28,7 \mathrm{mg} \mathrm{L}^{-1} ; \mathrm{K}=155 \mathrm{mg} \mathrm{dm}^{-3}$; $\mathrm{Ca}^{+2}=4,3 \mathrm{cmol}_{\mathrm{c}} \mathrm{dm}^{-3} ; \mathrm{Mg}^{+2}=1,1 \mathrm{cmol}_{\mathrm{c}} \mathrm{dm}^{-3} ; \mathrm{Al}^{+3}=0,0$ $\mathrm{cmol}_{\mathrm{c}} \mathrm{dm}^{-3} ; \mathrm{H}+\mathrm{Al}=2,64 \mathrm{cmol}_{\mathrm{c}} \mathrm{dm}^{-3} ; \mathrm{SB}=5,8 ; \mathrm{CTC}_{(\mathrm{t})}=5,8$;

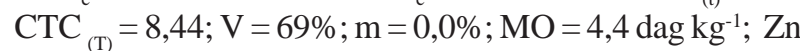
$=3,3 \mathrm{mg} \mathrm{dm}^{-3} ; \mathrm{Fe}=14,5 \mathrm{mg} \mathrm{dm}^{-3} ; \mathrm{Mn}=43,5 \mathrm{mg} \mathrm{dm}^{-3} ; \mathrm{Cu}=$ $0,5 \mathrm{mg} \mathrm{dm}^{-3}$ e $\mathrm{B}=0,3 \mathrm{mg} \mathrm{dm}^{-3}$.

Aos 40 dias antes do transplante das mudas, procedeu-se à correção do solo com calcário dolomítico, com base na saturação por bases, e, aos cinco dias antes do transplante, a adubação de fundação. Em razão da não existência de recomendação de calagem e de adubação para a cultura do pepino africano, a correção do solo e a adubação foram realizadas com base na análise química do solo e nas recomendações para a cultura do pepino (Cucumis sativus), para o Estado de Minas Gerais, conforme Ribeiro et al., (1999), exceto para a adubação nitrogenada.

Aplicou-se o equivalente a $300 \mathrm{~kg} \mathrm{ha}^{-1} \mathrm{de}_{2} \mathrm{O}_{5}, 90 \mathrm{~kg}$ $\mathrm{ha}^{-1}$ de $\mathrm{K}_{2} \mathrm{O}, 10 \mathrm{~kg} \mathrm{ha}^{-1}$ de bórax, $15 \mathrm{~kg} \mathrm{ha}^{-1}$ de sulfato de zinco, $10 \mathrm{~kg} \mathrm{ha}^{-1}$ de sulfato de cobre e $0,6 \mathrm{~kg} \mathrm{ha}^{-1}$ de molibdato de sódio. Na adubação de base, empregou-se o total da dose recomendada para todos os nutrientes, exceto para o $\mathrm{K}$ e para o $\mathrm{N}$, que foram parcelados. $\mathrm{O} \mathrm{K}$ foi todo aplicado em cobertura, em três parcelas, sendo a primeira de $30 \%$ e as duas restantes de $35 \%$, aplicadas, respectivamente, aos 15, 35 e 55 dias após o transplante das mudas (DAT).

Os tratamentos consistiram em seis doses de N, correspondentes a $0,40,80,120,160$ e $200 \mathrm{~kg} \mathrm{ha}^{-1}$, distribuídas no delineamento inteiramente casualizado, com 11 repetições. Semanalmente, os vasos eram mudados de posição dentro da casa de vegetação, para contornar possíveis efeitos diferenciais de ambiente. Cada repetição foi constituída de um vaso com uma planta cada, em vista das dificuldades de condução da planta amarrada ao suporte (estaca) de bambu. As doses de $\mathrm{N}$ foram definidas, tendo como referência a recomendada para a cultura do pepino (Cucumis sativus), que é de $130 \mathrm{~kg} \mathrm{ha}^{-1}$, para cultivo em ambiente protegido (Ribeiro et al., 1999). Essas doses foram parceladas da seguinte forma: $30 \%$, juntamente com a adubação de base, aos cinco dias antes do transplante das mudas; $25 \%$, aos 15 DAT; $25 \%$, aos 35 DAT e $20 \%$, aos 55 DAT, ou seja, conjuntamente com as parcelas de K.

Utilizaram- se, como fontes de nitrogênio e de potássio, respectivamente, o sulfato de amônio e o cloreto de potássio. Ambos os fertilizantes foram dissolvidos em água e a solução aplicada sobre o solo, ao redor da base das plantas, com auxílio de um copo. Procedeu-se à irrigação manualmente, com uma proveta, duas vezes ao dia. Foram colocados pratos sob os vasos para coleta de eventual solução drenada, a qual era reposta ao solo na parte superior do vaso.

A colheita dos frutos aconteceu de 04/02/2011 a 23/ 02/2011. O critério utilizado para a colheita foi o de os frutos começarem a apresentar coloração amarelo alaranjada na base dos espinhos. Os frutos colhidos foram contados e pesados, individualmente, na data de colheita, obtendo-se a massa de matéria fresca. Em laboratório, os frutos tiveram suas dimensões mensuradas, com um paquímetro digital (Digimess ${ }^{\circledR}$ ), com precisão de 0,01 $\mathrm{mm}$. A polpa foi retirada e, o rendimento de polpa, obtido pela diferença entre o peso da massa de matéria fresca do fruto e da polpa, expresso em percentagem. A polpa foi processada em um mix e, a partir do suco, foram avaliadas as características de qualidade de fruto, em termos de teor de sólidos solúveis (expresso em ${ }^{\circ}$ Brix), por meio de refratômetro digital portátil (Hanna Instruments ${ }^{\circledR}$, modelo HI 96801) e pH, utilizando-se o potenciômetro digital Digimed $^{\circledR}$. Após a última colheita dos frutos, as plantas foram cortadas rente ao solo, o sistema radicular arrancado e lavado para retirada do solo. A parte aérea e as raízes foram submetidas à secagem, em estufa, com circulação forçada de ar, a $65^{\circ} \mathrm{C}$, até peso constante, obtendo-se a massa de matéria seca.

Foram avaliadas as seguintes características: diâmetro e comprimento de fruto; número de frutos por planta; massa de matéria fresca de frutos por planta; massa média 
de matéria fresca de fruto; ${ }^{\circ} \mathrm{Brix}, \mathrm{pH}$ e rendimento de polpa; massas de matéria seca da parte aérea e das raízes e razão da massa de matéria seca de parte aérea/massa de matéria seca das raízes. Os dados obtidos foram submetidos à análise de regressão, utilizando-se o programa SAEG (SAEG, 2007). A escolha das equações deu-se com base no ajuste $\left(\mathrm{R}^{2}\right)$, na significância dos betas e na explicação biológica do fenômeno.

\section{RESULTADOS E DISCUSSÃO}

Houve efeito de doses de $\mathrm{N}$ para as características produção de massa de matéria fresca de frutos/planta, massa média de matéria fresca de frutos, número de frutos/planta e massa de matéria seca de parte aérea de planta, as quais apresentaram resposta quadrática às doses de $\mathrm{N}$ aplicadas (Tabela 1). Maior número estimado de frutos por planta (2,24 frutos/planta) foi alcançado com a dose de $122,50 \mathrm{~kg} \mathrm{ha}^{-1}$ de $\mathrm{N}$, enquanto a maior produção estimada em massa de matéria fresca de frutos/planta $(516,41 \mathrm{~g} /$ planta) foi obtida com a dose de $\mathrm{N}$ de $154,44 \mathrm{~kg} \mathrm{ha}^{-1}$.

A massa média de matéria fresca de fruto apresentou resposta quadrática às doses de $\mathrm{N}$ aplicadas; todavia, o ponto de máximo estimado $\left(209,00 \mathrm{~kg} \mathrm{ha}^{-1} \mathrm{de} \mathrm{N}\right)$ extrapolou a dose máxima trabalhada de $200 \mathrm{~kg} \mathrm{ha}^{-1} \mathrm{de} \mathrm{N}$. Com a dose máxima trabalhada (200 $\left.\mathrm{kg} \mathrm{ha}^{-1} \mathrm{de} \mathrm{N}\right)$, a massa média de matéria fresca de fruto estimada ficaria em 240,27 g/fruto, enquanto, com a dose para a máxima produtividade física $\left(154,44 \mathrm{~kg} \mathrm{ha}^{-1} \mathrm{de} \mathrm{N}\right)$, a massa média de matéria fresca de fruto estimada ficaria em 237,07 g/fruto e, o número de frutos/planta, igual a 2,18. Esse valor de massa média de fruto está abaixo dos 328,98 g/fruto encontrados por Souza et al. (2006), em frutos de pepino africano colhidos na Serra da Cantareira, em São Paulo, porém, em cultivo a campo.
A dose de $\mathrm{N}$ recomendada para a cultura do pepino comum (Cucumis sativus), no Estado de Minas Gerais ( $5^{\text {a }}$ Aproximação), para cultivo em ambiente protegido, é de $130 \mathrm{~kg} \mathrm{ha}^{-1}$, mais de 20 a $40 \mathrm{~m}^{3} \mathrm{ha}^{-1}$ de esterco bovino curtido (Ribeiro et al., 1999). Com base nas equações de regressão ajustadas, neste trabalho, para produção de matéria fresca de frutos/planta, número de frutos/planta e massa média de matéria fresca de fruto, a dose de $130 \mathrm{~kg} \mathrm{~N}$ $\mathrm{ha}^{-1}$, recomendada para o cultivo do pepino comum em ambiente protegido, proporcionaria a produtividade de frutos de 512,22 g/planta, número de 2,22 frutos/planta, com massa média de 233,47 g/fruto, respectivamente. Portanto, esses valores estão próximos dos encontrados neste trabalho.

Todavia, para pepino japonês, Pôrto et al. (2011b) obtiveram máxima produtividade com a dose de $406 \mathrm{~kg} \mathrm{~N}$ ha $^{-1}$, o que sugere que a recomendação da $5^{\mathrm{a}}$ Aproximação para a adubação nitrogenada do pepino está subestimada. Porém, considerando-se que na $5^{\mathrm{a}}$ Aproximação recomenda-se aplicar, além da fertilização mineral, de 20 a 40 $\mathrm{m}^{3} \mathrm{ha}^{-1}$ de esterco bovino curtido, e que o esterco tem cerca de $75 \%$ de matéria seca, com teor de $\mathrm{N}$ na matéria seca de 1,7\% (Ribeiro et al., 1999), ao se adicionarem $30 \mathrm{~m}^{3}$ $\mathrm{ha}^{-1}$ de esterco bovino curtido, estariam sendo fornecidos mais cerca de $382 \mathrm{~kg}$ de $\mathrm{N} \mathrm{ha}^{-1}$, ultrapassando a dose encontrada por Pôrto et al. (2011b).

Aumentos de produtividade em resposta às doses de $\mathrm{N}$, como resultado do aumento do número de frutos/planta e, ou, da massa média de fruto em outras cucurbitáceas, foram observados nas culturas da melancia (Andrade Junior et al., 2006), melão (Queiroga et al., 2007) e maxixe (Oliveira et al., 2008). Máximas produtividades físicas foram encontradas com doses de $\mathrm{N}$ de $260 \mathrm{~kg} \mathrm{ha}^{-1}$, para

Tabela 1. Equações de regressão ajustadas para características de planta e de frutos de pepino africano em resposta à adubação nitrogenada

\begin{tabular}{llc}
\hline Característica $^{1}$ & Equação de regressão & $\mathbf{R}^{\mathbf{2}}$ \\
\hline MFF (g/planta) & $\hat{\mathrm{Y}}=308,91+2,6872 * \mathrm{x}-0,0087 * \mathrm{x}^{2}$ & 0,8175 \\
MFMF (g/fruto) & $\hat{\mathrm{Y}}=192,25+0,4601 * \mathrm{x}-0,0011^{*} \mathrm{x}^{2}$ & 0,8141 \\
NFP (N/planta) & $\hat{\mathrm{Y}}=1,6266+0,0098^{*} \mathrm{x}-0,00004 * \mathrm{x}^{2}$ & 0,6291 \\
MSPA (g/planta) & $\hat{\mathrm{Y}}=32,903+0,0288 * \mathrm{x}+0,0001 \mathrm{x}^{* 2}$ & 0,8951 \\
MSR (g/planta) & $\hat{\mathrm{Y}}=0,66$ & \\
MSPA/MSR & $\hat{\mathrm{Y}}=66,61$ & \\
CF (mm) & $\hat{\mathrm{Y}}=108,47$ & \\
DF (mm) & $\hat{\mathrm{Y}}=68,46$ & \\
RP $(\%)$ & $\hat{\mathrm{Y}}=59,64$ & \\
pH & $\hat{\mathrm{Y}}=4,45$ & \\
SST $(\%)$ & $\hat{\mathrm{Y}}=4,80$ & \\
\hline
\end{tabular}

${ }^{1}$ Característica: MFF = massa de matéria fresca de frutos por planta; MFMF = massa de matéria fresca média de fruto; NFP = número de frutos/planta; MSPA = massa de matéria seca da parte aérea de planta; MSR = massa de matéria seca de raízes; MSPA/MSR = razão da massa de matéria seca de parte aérea/ massa de matéria seca de raízes; $\mathrm{CF}=$ comprimento de fruto; $\mathrm{DF}=$ diâmetro de fruto; $\mathrm{RP}=$ rendimento de polpa de fruto; $\mathrm{pH}=\mathrm{pH}$ de polpa e SST = teor de sólidos solúveis totais na polpa de frutos de pepino africano (Cucumis metuliferus).

* = significante, pelo teste $\mathrm{t}$, a $5 \%$ de probabilidade. 
abóbora híbrida tipo ‘Tetsukabuto' (Pôrto et al., 2011a), de $331 \mathrm{~kg} \mathrm{ha}^{-1}$, para abobrinha cv. Caserta (Pôrto et al., 2012), de 312 e de $344 \mathrm{~kg} \mathrm{ha}^{-1}$, para o melão Cantaloupe, em ambiente protegido e a campo, respectivamente (Coelho, et al., 2003) e de 287, 1 a $309,7 \mathrm{~kg} \mathrm{ha}^{-1}$ para duas variedades de melão Cantaloupe cultivadas em ambiente protegido (Queiroga et al., 2007).

Nas espécies do gênero Cucumis, das quais fazem parte os pepinos e os melões, exceto para meloeiro cultivado nos Tabuleiros Costeiros do Piauí (Sousa et al., 2005) e em Vertissolo (Faria et al., 2000), para que foram obtidas máximas produtividades com 160 e $180 \mathrm{~kg} \mathrm{~N} \mathrm{ha}^{-1}$, respectivamente, as doses de $\mathrm{N}$ para máximas produtividades física das culturas desse gênero estão acima da encontrada, aqui, para o pepino africano, sugerindo que Cucumis metuliferus é menos exigente em N que outras cucurbitáceas desse gênero.

A produção de massa de matéria seca de parte aérea das plantas apresentou o máximo estimado de 39,12 g/ planta com a dose $144,00 \mathrm{~kg} \mathrm{~N} \mathrm{ha}^{-1}$, ou seja, um pouco abaixo da dose de $154 \mathrm{~kg}$, que proporcionou máximo de produção de frutos/planta (Tabela 1). Todavia, não houve efeito de doses de $\mathrm{N}$ sobre a produção de massa de matéria seca de raízes nem na razão de massa de matéria seca parte aérea/raízes, com valores médios 0,66 g/planta e 66,61, respectivamente.

Também não houve efeito de doses de $\mathrm{N}$ sobre as características relacionadas com os frutos, comprimento e diâmetro, rendimento de polpa, $\mathrm{pH}$ e teor de sólidos solúveis totais (Tabela 1). Os valores encontrados para diâmetro e comprimento de fruto foram semelhantes aos encontrados por Romero-Rodriguez et al. (1992), Benzioni et al. (1993) e Marsh (1993). Porém, Souza et al. (2006) obtiveram frutos com diâmetro e comprimento de 70,98 $\mathrm{mm}$ e $114,54 \mathrm{~mm}$, respectivamente, pouco maiores, portanto, que os valores aqui encontrados.

Valores inferiores para rendimento de polpa $(48,96 \%)$, de sólidos solúveis totais $\left(3,03{ }^{\circ} \mathrm{Brix}\right)$ e de $\mathrm{pH}(4,13)$ são mencionados para pepino africano na literatura. Contudo, Benzioni et al. (1993) encontraram valores de sólidos solúveis totais e de $\mathrm{pH}$ próximos ao deste trabalho, e Romero-Rodriguez et al. (1992) encontraram valor de sólidos solúveis de $8,3^{\circ}$ Brix, porém com a mesma faixa de $\mathrm{pH}$.

Variações relacionadas com a composição química dos frutos podem ser devidas às condições climáticas dos ambientes de cultivo, bem como aos distintos materiais genéticos utilizados nessas pesquisas, haja vista, ainda não existirem trabalhos de caracterização desses materiais. Todavia, com base nos dados obtidos neste trabalho, em razão de os frutos não apresentarem diferença na qualidade, em resposta às doses de nitrogênio testadas, a qualidade de fruto parece não ser um fator limitante para a decisão da dose de $\mathrm{N}$ a ser aplicada na cultura.

\section{CONCLUSÃO}

A dose de $\mathrm{N}$ para maior produtividade física do pepino africano (Cucumis metuliferus) é de 154,44 $\mathrm{kg} \mathrm{ha}^{-1}$, com a qual se obtêm 2,18 frutos/planta, frutos com adequado padrão comercial, com massa média igual a 237,07 g/fruto.

\section{AGRADECIMENTOS}

À FAPEMIG e ao CNPq, pelo apoio para realização da pesquisa.

\section{REFERÊNCIAS}

Andrade Junior AS, Dias NS, Figueiredo Junior LGM, Ribeiro VQ \& Sampaio DB (2006) Produção e qualidade de frutos de melancia à aplicação de nitrogênio via fertirrigação. Revista Brasileira de Engenharia Agrícola e Ambiental, 10:836-841.

Barros MM, Araújo WF, Neves LTBC, Campos AJ \& Tosin JM (2012) Produção e qualidade da melancia submetida a adubação nitrogenada. Revista brasileira de engenharia agrícola e ambiental, 16:1078-1084.

Benzioni A (1997) Kiwano (Cucumis metuliferus). Disponível em: <http://www.hort.purdue.edu/newcrop/cropfactsheets/ kiwano.html>. Acessado em: 25 de abril de 2011.

Benzioni A, Mendlinger S, Ventura M \& Huyskens S (1993) Germination, fruit development, yield, and postharvest characteristics of Cucumis metuliferus. In: Janick J \& Simon JE (Eds.) New Crops. New York, John Wiley. p.553-557.

Coelho EL, Fontes PCR, Finger FL \& Cardoso AA (2003) Qualidade do fruto de melão rendilhado em função de doses de nitrogênio. Bragantia, 62:173-178.

Faria CMB, Costa ND, Pinto JM, Brito LTL \& Soares JM (2000) Níveis de nitrogênio por fertirrigação e densidade de plantio na cultura do melão em um Vertissolo. Pesquisa agropecuária brasileira, 35:491-495.

Fogaça MAF, Andriolo JL, Godoi RS, Gieh RFH, Madaloz JCC \& Barros GT (2007) Concentração de nitrogênio na solução nutritiva, na produtividade e na qualidade de frutos de melão cultivado em substrato. Ciência Rural, 37:72-78.

Huett DO \& Dettmann EB (1991) Nitrogen response surface models of zucchini squash, head lettuce and potato. Plant and Soil, 134:243-254.

Jimam NS, Wannang NN, Omale S \& Gotom B (2010) Evaluation of the hypoglycemic activity of Cucumis metuliferus (Cucurbitaceae) fruit pulp extract in normoglycemic and alloxaninduced hyperglycemic rats. Journal Young Pharmacists, 2:384387.

Marschner H (1986) Mineral nutrition of higher plants. San Diego, Academic Press. 674p.

Marsh DB (1993) Evaluation of Cucumis metuliferus as a specialty crop for Missouri. In: Janick J \& Simon JE (Eds.) New Crops. New York, John Wiley. p.558-559.

NRC - National Research Council (2008) Lost Crops of Africa. Volume III. Washington DC, The National Academies Press. $353 \mathrm{p}$.

Oliveira AP, Oliveira ANP, Alves AU, Alves EU, Silva DF, Santos RR \& Leonardo FAP (2008) Rendimento de maxixeiro adubado com doses de nitrogênio. Horticultura Brasileira, 26:533-536. 
Pôrto MLA, Puiatti M, Fontes PCR, Cecon PR, Alves JC \& Arruda JA (2012) Produtividade e acúmulo de nitrato nos frutos de abobrinha em função da adubação nitrogenada. Bragantia, 71:190-195.

Pôrto MLA, Puiatti M, Fontes PCR, Cecon PR, Alves JC \& Faustino VA (2011a) Produtividade da abóbora híbrida tipo "Tetsukabuto" em função da adubação nitrogenada. In: $51^{\circ}$ Congresso Brasileiro de Olericultura, Viçosa. Anais, ABH. CD ROM.

Pôrto MLA, Puiatti M, Fontes PCR, Cecon PR, Alves JC \& Faustino VA (2011b) Produtividade do pepino japonês em função da adubação nitrogenada em ambiente protegido. In: $51^{\circ}$ Congresso Brasileiro de Olericultura, Viçosa. Anais, ABH. CD ROM.

Queiroga RCF, Puiatti M, Fontes PCR, Cecon PR \& Finger FL (2007) Influência de doses de nitrogênio na produtividade e qualidade do melão Cantalupensis sob ambiente protegido Horticultura Brasileira, 25:550-556.

Ribeiro AC, Guimares H \& Alvarez V VH (1999) Recomendações para uso de corretivos e fertilizantes em Minas Gerais - 5 Aproximação. Viçosa, CFSEMG. 359p.

Robinson RW \& Decker-Walters DS (1997) Cucurbits. New York, CAB International. 226p.

Romero-Rodriguez MA, Vazquez-Oderiz ML, Lopez-Hernandez J \& Simal-Lozano J (1992) Physical and Analytical Characteristics of the Kiwano. Journal of Food Composition and Analysis, 5:319-322.
SAEG (2007) Sistema para Análises Estatísticas. Versão 9.1. Viçosa, UFV. CD ROM.

Santos GR, Castro Neto MD, Almeida HSM, Ramos LN, Sarmento RA, Lima SO \& Erasmo EAL (2009) Effect of nitrogen doses on disease severity and watermelon yield. Horticultura Brasileira, 27: 330-334

Sigüenza C, Schochow M, Turini T \& Ploeg AT (2005) Use of Cucumis metuliferus as a Rootstock for Melon to Manage Meloidogyne incognita. Journal of Nematology, 37:276-280.

Sousa VF, Coelho EF, Souza VAB \& Holanda Filho RSF (2005) Efeitos de doses de nitrogênio e potássio aplicadas por fertirrigação no meloeiro. Revista brasileira de engenharia agrícola e Ambiental, 9:210-214.

Souza AD, Pinto PM, Borkoski AC, Mezzacapa FL, D'Andrea F, Sacchetto Júnior LPM \& Biato M (2006) Caracterização de frutos de Cucumis metuliferus na Serra da Cantareira, São Paulo. Thesis, 5:147-160.

Wannang NN, Jimam NS, Omale S, Dapar MLP, Gyang SS \& Aguiyi JC (2007) Effects of Cucumis metuliferus (Cucurbitaceae) fruits on enzymes and haematological parameters in albino rats. African Journal of Biotechnology, $6: 2515-2518$.

Xu G, Fan X \& Miller AJ (2012) Plant Nitrogen Assimilation and Use Efficiency. Annual Review of Plant Biology, 63:153-182. 